\title{
La semilla y el camino de la palabra en gestación \\ Tres voces, tres maestros, tres fuentes \\ Homenaje a tres maestros de las letras en Colombia: \\ Alix Amaya Becerra, Isaías Peña Gutiérrez \\ y Beethoven Herrera Valencia
}

\author{
por Laura Buitrago Niño y Enrique Ferrer-Corredor
}

\begin{abstract}
La educación es el único medio de movilización social en una sociedad tan injusta como la nuestra.

Un homenaje a tres grandes docentes de nuestra comunidad colombiana. Su testimonio, desde tres escenarios muy diversos, nos hace rastrear la huella labrada por años con generaciones de niños y jóvenes, quienes hoy representan, con su quehacer, el legado de sus maestros. Este es un reconocimiento para quienes, ya fuese en la escuela, ya en la universidad, guiaron nuestras primeras letras.
\end{abstract}

\section{Profesora Alix Amaya Becerra}

Los primeros miedos son descifrados por la madre y por los maestros de la escuela, en esa patria que es la infancia. La profesora Amaya nunca sucumbió ante el peligro del paisaje en el Colegio Agustín Nieto Caballero, junto a la plaza España, en el centro de Bogotá. Su compromiso, riesgo, solidaridad y comprensión la llevaron a entregar su sonrisa eterna cada año a un puñado de niños, cuyos cuerpos y premuras para saciar el hambre eran todo su equipaje. Nutrió su sensibili-

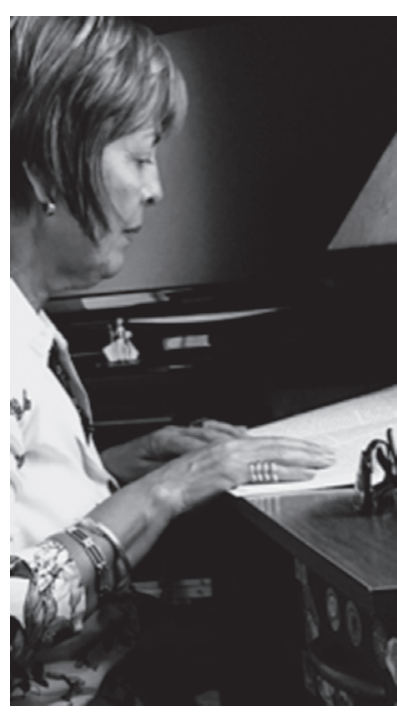

esperanza a innumerables generaciones de infantes en sus primeros pasos, en sus primeras letras. La señorita Alix fundó realidades en sus pupilos, les enseñó las posibilidades del mundo a través del tejido de las palabras, posibilitó la capacidad de viajar a través de los libros; la escuela era un oasis en medio de la violencia alrededor del colegio, la selva de cemento arrojaba cientos de huérfanos de amor a sus pupitres. Su pasión por construir una sociedad distinta caminaba junto a la mujer, la maestra y la amiga; la compañera dad en las ciencias sociales de la UNAL en el ámbito de todas las revoluciones de los 70. Ya en el aula era la señorita Alix, con sus cimientos forjados en una familia bogotana labrada por la bondad y el respeto por el otro, por el pan siempre trabajado y compartido. $\mathrm{Su}$ rostro siempre en diálogo abrió caminos de 
No, no lo cambiaría; fue mi oficio, siento que fui feliz desempeñándome en esta labor. No obstante, con el paso del tiempo se fue mejorando de una educación memorística a un aprendizaje más participativo, más reflexivo, deductivo, en el que el juego como herramienta cumplió con la experimentación y la satisfacción compartida.

En los últimos veinte años la concepción de lo que se quiere en educación se ha incentivado desde la academia y las políticas públicas, por supuesto falta mejorar, pero se ha avanzado.

Ya las clases magistrales han sido superadas por la participación, haciendo que el estudiante sea el protagonista del aprendizaje, la experimentación, la creatividad, inclusive aprendiendo del error.

2. ¿Cuáles han sido los mayores cambios en la educación, positivos y negativos, entre los tiempos en que usted fue educada y hoy?

El mayor cambio ha sido en los métodos, en cuanto que la memorización, la repetición han sido superados por la experimentación, por los procesos deductivos, por la evolución cualitativa que integra relaciones cognitivas, motrices, analíticas y sociales, y lleva al estudiante a pensarse y conocerse en sus habilidades y destrezas, pero también en sus deficiencias.

En mi concepto, la forma de evaluación cualitativa crea un abanico más amplio de reconocimientos del otro, de los parámetros del conocimiento de manera puntual y eficaz; y asume la integralidad del estudiante en sus procesos cognitivos, creativos, motrices y sociales.

Hay que apoyarse en los medios tecnológicos como herramienta global que amplía e inscribe al estudiante en el mundo de hoy. En cuanto la parte "negativa", sería seguir empujando el carro de las políticas públicas en cuanto a mejorar las instalaciones educativas, las oportunidades tanto de inscripción al sistema educativo como de retención de los estudiantes y culminación de los estudios básicos, para luego, no solo inscribirse en el mundo académico, sino abrir puertas en el mercado laboral.

3. ¿Cuáles son los mayores cambios en los hábitos, técnicas, propósitos de lectura y la escritura hoy, respecto a la época de sus estudios?

Los niños de hoy aprenden la lectura y la escritura de manera comprensiva, apoyados en métodos que los inscriben en su entorno, en contextos cercanos a sus intereses, a sus deseos y experiencias, superando así la repetición, la memorización, el método silábico y construyendo procesos de análisis, argumentación y deducción, mejorando así la oralidad y el conocimiento del mundo que los rodea.

4. La motivación es algo esencial en el aprendizaje. ¿Pero no cree usted que la enseñanza se ha concentrado más en la memorización que en la comprensión? Y es que solo un maestro que sabe motivar logra llevar por el camino de la comprensión, ¿no?

Antes sí. Pienso que ahora los procesos han cambiado, pienso, de manera sustancial. Eso no quiere decir que la memoria no juegue un papel importante; subyace en el aprendizaje, pero los procesos de experimentación, deducción y argumentación hoy se hacen presentes y el aprendizaje se inscribe de manera significativa.

Las evaluaciones dan cuenta de ello. Las pruebas a nivel nacional, como las pruebas Saber Pro, contienen en sí mismas la concepción de procesos que conllevan al estudiante a responder de manera deductiva y argumentativa de modo que el conocimiento, los datos, la información, no son cabos sueltos, sino que obedecen a un trabajo de procesos que involucran la experiencia y la deducción.

5. ¿Cómo ha cambiado su método de enseñanza en el transcurso de sus años de experiencia? 
Notablemente, procurando en cada momento más comprensión del estudiante como la persona que es, que está en disposición de socializar, de aprender y reconocer sus habilidades. Tratando de poner en práctica nuevos métodos, nuevas formas de evaluar. Las capacitaciones, la investigación y la academia contribuyen positivamente a mejorar los procesos de enseñanza-aprendizaje de manera integral, tanto en las metas propuestas como en los métodos de evaluación, que en últimas dan cuenta del esfuerzo propuesto por los integrantes del proceso educativo.

6. ¿Considera muy dependiente el aprendizaje de los chicos con respecto a sus padres o familia, o piensa que este hecho se ha liberado con la tecnología? Y en este sentido, ¿qué tan definitiva considera la influencia de la familia en el proceso de formación en los primeros años de escuela de los estudiantes?

Depende mucho del nivel socioeconómico de las familias, de las ayudas y el acompañamiento, no solo en la realización de tareas, aprendizajes, sino en la crianza y crecimiento de los estudiantes. En los sectores más deprimidos se tiene la idea de que el estudiante debe hacer como el maestro dice, más como un deber, como lo que se tiene que hacer, sin acompañamiento ni dirección.

7. ¿Se puede decir que hay algo más fácil de enseñar en la lectoescritura y algo más difícil; o hay un equilibrio en la complejidad del desarrollo de las cuatro habilidades básicas: hablar, escuchar, leer y escribir?

Aprender a escribir es un acto de copia de un modelo (símbolo) que representa un fonema y leer es un acto de memoria con respecto a los sonidos. La complejidad del acto de la lectoescritura en sus primeros inicios se asume con la memorización, la mecánica repetitiva, las asociaciones y la creatividad que juega un papel muy importante sin olvidar los intereses de los estudiantes y su inscripción en los contextos; todo en conjunto da como resultado el proceso lector-escritor, hablante-escucha.

8. ¿Cuál es el caso más raro (difícil o asombroso, o ambos) que ha tenido como profesora?

En los inicios de mi carrera magisterial se me presentó un niño que de pronto ya era grande para estar en primero de primaria; nadie quería que ese niño estuviera en su curso. Había muchas razones para eso. Las maestras decían: "quédate tú con él".

El niño tenía muchas dificultades de aprendizaje, pero no porque él mismo las tuviera; es decir, no era un límite de la parte cognitiva, era falta de afecto en el colegio. Me di cuenta de ello por algo, él me decía: "¿usted me deja izar bandera?" Y le dije: "sí, yo sí te dejo". Pero es que imagínense un niño que hizo cuatro veces primero de primaria y nunca pasó. Fue algo intuitivo mío, ya que no tenía conocimiento de cómo manejar la situación, ni había apoyos profesionales. Entonces le puse una condición para que izara bandera: él me tenía que cumplir con las cosas de la clase. El niño ya sabía, el niño sí sabía, pero no podía decirlo; yo creo que los maestros que él tenía antes eran muy fuertes, muy exigentes y no comprendían su parte de niño, del miedo que sentía cuando iba a decir las cosas. Lo único que resta por decir es que el niño ya sabía, que el niño había aprendido, y fue promovido al siguiente curso, además con todo el amor del mundo, era un niño súper afectivo.

Y la otra fue una experiencia que hicimos nosotras (las maestras) en el colegio, porque veíamos muchos niños que perdían lectoescritura. En ese momento ya había una psicóloga, una mujer muy pila, y empecé a trabajar con ella, a comentar los problemas de los chicos; y veíamos que no solo eran los niños de mi grupo. Al siguiente año, durante todo el periodo académico hicimos un curso con niños que tuviesen algunas 
dificultades en particular, yo fui la maestra. Teníamos un seguimiento muy constante, todos los días. Descubrimos que muchos de estos niños tenían unos problemas psicológicos, por muchos motivos, especialmente familiares; otros por problemas de retraso mental (pero eso no se tenía en cuenta en ese entonces). Fue muy exitoso el programa, en la medida en que los niños pudieron vocalizar mejor, que tuvieron un mayor acercamiento a la lectoescritura; y que nosotros comprendimos que los niños no solo se comunicaban por medio de la escritura, sino por canto, dibujos, con arte; y que podían desarrollar muchas otras habilidades.

\section{Profesor Isaías Peña Gutiérrez}

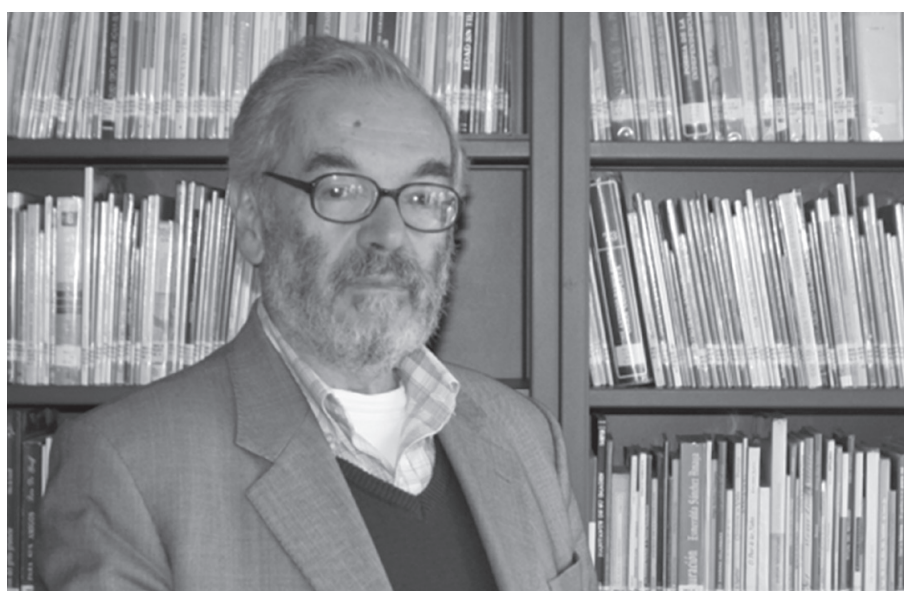

Alguna vez Isaías le preguntó a Fernando Gaitán en la entrevista para ingresar al Taller de Escritores de la Universidad Central si conocía alguna escritora colombiana importante, y este le contestó: "sí, mi sobrina". Isaías le indagó por su nombre y sus libros. Y Fernando le dijo: "todavía no ha publicado, tiene 5 años, pero es la escritora más importante en mi vida". La sonrisa de Isaías, su mirada esparcida en el horizonte y su confianza en el proyecto de su vida dieron la bienvenida al joven discípulo. El maestro Isaías Peña ha impartido el amor por las letras a los aprendices de escritores por muchos años. Desde el TEUC, ese bello espacio para forjar la imaginación, desde comienzos de los 80 , se erigió el maestro Peña en el icono de los espacios para fomentar la escritura literaria en Colombia. Cientos de escritores colombianos han pasado y siguen labrando sus primeros cuentos, poemas, sus obras, en el TEUC. Su arduo trabajo ha ampliado la apuesta a un programa de pregrado, ya incluso con maestría en el campo de la creación literaria.

1. Si usted volviera a nacer: ¿cambiaría su oficio de profesor?, ¿o qué cambiaría de lo que hizo usted en sus primeros años como profesor?

Nunca quise ser profesor. Renuncié a la Normal para ser un profesional. Cuando comenzó la vida, Fernando Hinestroza, rector de la Universidad Externado de Colombia, donde había yo estudiado Derecho, me ofreció una plaza de profesor. La acepté y me fue bien. Allí comenzó la cosa. Y siguiendo la ruta de la vida, jamás fui solamente profesor. De hecho, cuando comencé a serlo, ya era escritor y periodista y ensayista y crítico y comentarista y gacetillero y entrevistador y gestor cultural y promotor de lectura. Siempre he sido un investigador nato. Contra canonista puro. Eso me ha permitido no ser un dictador de clases, sino un explorador que comparte con los estudiantes el ansia de lo que no ha sido descubierto.

2. ¿Cuáles han sido los mayores cambios en la educación, positivos y negativos, entre los tiempos en que usted fue educado $y$ hoy?

No ha cambiado mucho. Cuando fundé el Taller de Escritores lo hice porque quería escapar al corset burocrático de la educación. Cuando, con base en la experiencia e 
investigaciones con el Taller de Escritores, hice la parrilla de materias para la carrera de Creación Literaria y consolidé una didáctica, un método y un pensamiento distinto de exploración del conocimiento, me estrellé con el pasado. A los estudiantes y al profesor les encanta la seguridad del canon, el rejo de las notas, el sufrimiento de las correcciones, la pasividad del salón, la rutina gloriosa de la biblia que cada profesor profesa.

3. ¿Cuáles son los mayores cambios en los hábitos, técnicas, propósitos de lectura y la escritura hoy, respecto a la época de sus estudios?

En los últimos 20 años, Colombia ha intentado ampliar el frente de acceso a la mejor lectura. No fue vana la fundación del taller de Manuel Mejía Vallejo en Medellín y del TEUC, en Bogotá, en 1981. Hoy tenemos una red distrital y nacional de talleres de lectura y escritura. Debería ser mejor estructurada, con menos TIC y más liberación. Eso, me parece, es lo que siento y veo, nos da un índice mayor de lectura y escritura entre jóvenes y viejos. Estamos lejos de Argentina, pero hemos disminuido la diferencia.

4. La motivación es algo esencial para el joven escritor. ¿Tenemos hoy la misma motivación para los escritores que hace 30 años?

La motivación para el lector siempre será compleja e integral, hace parte de una cultura total, salvo aquellos casos en los que, pareciera, la motivación surgiera por razones genéticas. Cuando haya más padres, madres, tíos y más profesores leyendo y escribiendo, tendremos más muchachos leyendo y escribiendo. Algunos leen y escriben motivados por las nuevas tecnologías. Ojalá estemos avanzando.

5. ¿Cómo ha cambiado su método de enseñanza en el transcurso de sus años de experiencia, en particular en relación con la lectura y escritura literaria?
También, en la investigación de estas décadas me he reafirmado en la creencia de que no se enseña a leer y a escribir mediante teorías crípticas o recetas de mecánica popular. Los procesos de lectura y de escritura, enseñan más. Leer bien, entender bien, sincronizar relaciones, seleccionar lo elemental, enseña a escribir. Y si se trata de la creación literaria -a la cual llegamos estudiando la evolución transgresora de la práctica literaria-, a ella llegamos solo cuando se ha aprendido a leer con sentido creativo, acumulando lo suficiente para llegar a la sabiduría -que no se enseña ni se aprende en una lección de clase.

6. ¿Cuál es la mayor diferencia entre los estudiantes de literatura de los 80, de los 90, y los de hoy?

Yo veo diferencia entre los estudiantes que hoy hacen creación literaria (que otros mal llaman "escrituras creativas"), y los antiguos estudiantes de literatura. Aquellos repetían la biblia; estos, han roto las bridas.

7. ¿Ha cambiado la enseñanza de la literatura? ¿Son bienvenidos esos cambios?

Creo que ya está respondido.

8. ¿Cuál es el caso más raro (difícil o asombroso, o ambos) que ha tenido como profesor?

Alguna vez, un estudiante que me estimaba mucho, me increpó en un parqueadero porque - me lo dijo- yo no le había enseñado todo lo que yo sabía. A veces, pienso que él venía de la otra educación y creía que yo era una enciclopedia y debía vaciar en él todo ese contenido. Mi fuerte ha sido provocar, mediante procesos de conocimiento, la capacidad libertaria y creadora del ser humano, sin desconocer la bondad.

9. ¿Se arrepiente de algo como profesor en los talleres de la U. C.?

Lamento, comienzo a lamentarlo, que nunca haya podido escribir lo que logro transmitir en una sesión (no me gusta 
decir "clase", nunca "dicto clase" y me entristece cuando ellos asisten a "clase", eso que convierte al salón en una prisión con vigilancia y disciplina) con los muchachos, en el Taller de Escritores o en el pregrado de Creación Literaria. No me arrepiento de nada; lamento la fugacidad de esos momentos; eso podría explicar la depresión y la soledad que siento cada vez que termino una reunión con ellos.

\section{Profesor Beethoven Herrera Valencia}

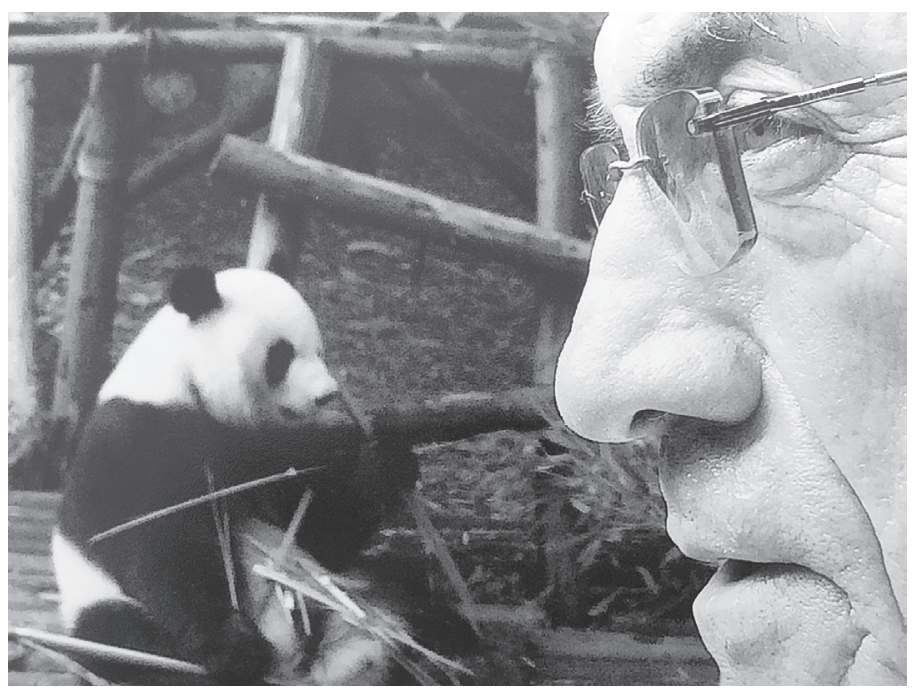

Todo lo llaman el profesor Beethoven, porque ya es legendario en la Facultad de Economía de la UNAL, porque su nombre oculta su apellido. Su perseverancia, su trabajo y su entrega al conocimiento suman ya décadas de oficio, como profesor, como investigador, como economista; pero sobre todo, como un viajero incansable en busca de aventura. No encuentras un estudiante de economía de la UNAL, del Externado, que no recuerde una anécdota con el profesor Beethoven Herrera. Tras muchos años de trasegar por las aulas, construyendo académicos de las ciencias sociales, su voz expresa el diálogo y la asimilación frente al cambio abrupto de las últimas generaciones. Un verdadero maestro se actualiza con sus estudiantes, Beethoven sigue siendo un buen estudiante de la vida.

1. Si usted volviera a nacer: ¿cambiaría su oficio de profesor?, ¿o qué cambiaría de lo que hizo usted en sus primeros años como profesor?
Me crié con cinco hermanos y cinco primos, de modo que crecimos once muchachos, de modo que era necesario definir qué iba a hacer cada uno (...) y yo desde muy niño me sentía muy bien ante el público, porque hacía teatro, cantaba en el coro de la escuela, estaba en grupo de danza, hacía misiones; y ese proceso de estar con la gente me llevó a sentir que yo tenía algún interés en transmitir un mensaje, fue la semilla inicial. Sentir que tenía interés por estar con la gente, en esa época a través de un mensaje, que era el modo de hacer solidaridad con las comunidades.

Desde muy niño tuve claro que quería ser un comunicador, fui predicador del evangelio cuando era jovencito, misionero en varios países; de modo que la educación fue y es una forma de entender esa misión. Además de haber visitado unos 80 países y ver que hay formas sociales diferentes, pasé del objetivo inicial de ser el transmisor de un mensaje, a la idea de hacer una transmisión más cultural que religiosa, más humanista que teológica.

2. ¿Cuáles han sido los mayores cambios en la educación, positivos y negativos, entre los tiempos anteriores en que enseñó y hoy? ¿Y cuál es la mayor diferencia entre los estudiantes de los 80, de los 90, y los de hoy?

Yo tuve en mi faro de clase a Jaime Garzón, Claudia López, Javier Díaz, María Consuelo Araujo, Iván Duque, Jaime Muñoz, y lo que ellos dicen cuando me encuentran, es que algo hubo diferente en la forma en que hacía las clases. Se dijo hace 20 días en una reunión de profesores "solo Beethoven hacía pruebas orales", y yo me preguntaba: ¿acaso 
ahora no sigue siendo así? ¿Cuántos profesores le dicen a los estudiantes: "saquen una hoja"? Y en la asamblea de socios de una empresa, frente a los accionistas, o cuando sea edil, o en la multinacional o en una empresa, va a tener que hablar; pero ninguna carrera tiene el desarrollo de esa facultad. Digamos, una egresada: la jefe, de la Nacho, viene y tiene muy buen desarrollo mental pero la mano le tiembla al saludar; como no es bilingüe, no estuvo en campamentos en Miami, no es hija de senador, ni viene de colegio internacional, su única facultad es tener esa capacidad bien puesta, pero si no habla bien, y no escribe bien, ¿cómo el mercado sabe de qué es capaz ella?

El mundo ha cambiado por cosas muy profundas, quizás las tres más profundas son: primero, el profundo cambio tecnológico: el engaño es creer que eso es conocimiento y no, es una herramienta; pero si no hay crítica, ni aplicación, no hay balance, no hay comparación, ni retroalimentación, solo son datos. Segundo, los impactos de lo anterior en la economía; como la contratación de servicios por internet o la compra de bienes, y con eso nadie puede luchar. Además, la mayoría tiene computador, acceso a la red, o las regala el gobierno, pero el error es creer que eso es educación, porque el instrumento no hace conocimiento, se debe tener una disciplina para eso. El tercer cambio, es que antes no se pasaba por la cabeza el cambio climático. Hay una agenda nueva que en mi generación no existía, es el tema de la naturaleza. Por ejemplo, nosotros en nuestra época teníamos una simpatía por los indígenas, pero el tema de la consulta previa para un proyecto de desarrollo se vuelve un lío para el gobierno, no sabe cómo manejarlo.

Y otro cambio, el más doloroso, creo yo, es que en mi generación nuestra obsesión era cambiar el sistema. Yo estuve en Corea del Norte, yo hice cartillas para la guerrilla, yo hacía paros con sindicatos, viví con los indígenas, anduve por el mundo, confiando en que mundo diferente fuera posible, que yo tenía que apostarle a eso. A uno no se le pasaba por la mente suicidarse, en esta generación, el suicidio es una opción. Yo le voy a preguntar: ¿tienen los jóvenes hoy en día motivación para pagar impuestos para las megas pensiones de los magistrados, para el robo de Odebrecht y Saludcoop? ¿Tienen los estudiantes motivación para ser correctos si todos son delincuentes en la estructura de la política?

Entonces el paisaje cambia brutalmente, los jóvenes ya no quieren un trabajo fijo; mi generación quería un trabajo estable. No una estadía laboral para conseguir ingreso y viajar; hoy los jóvenes quieren experimentar cosas nuevas y no se aferran a una forma de empleo permanente actual, ya no está la lógica de pensionarse y de tener carro. La ventaja de la tecnología es impresionante en comparación con mi época, y la posibilidad de viajar; pero esto se junta con infamias, como tener que vivir con el sida o la amenaza de la guerra nuclear, esto ha hecho que haya una pérdida del sentido de esperanza que en nuestra generación era todo lo contrario, había exceso de idealismo. Para esta generación es el desencanto de los países contaminados,

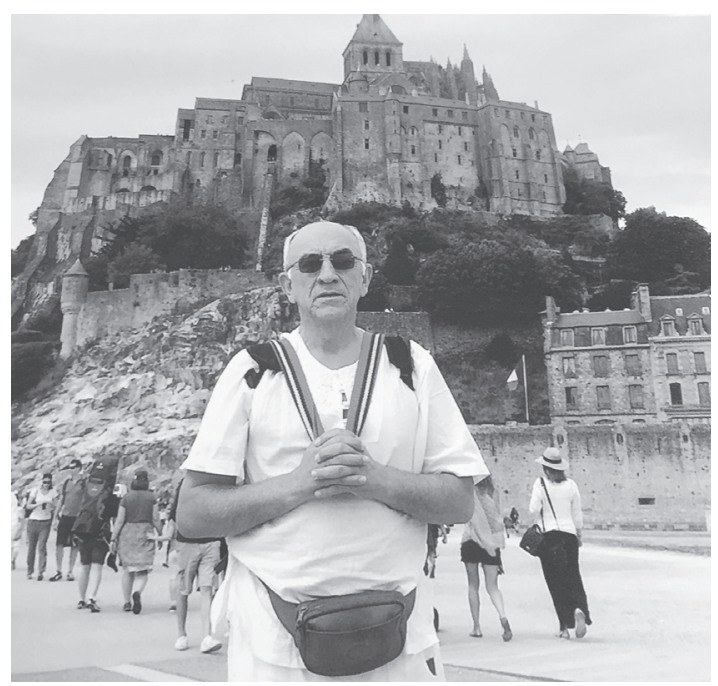




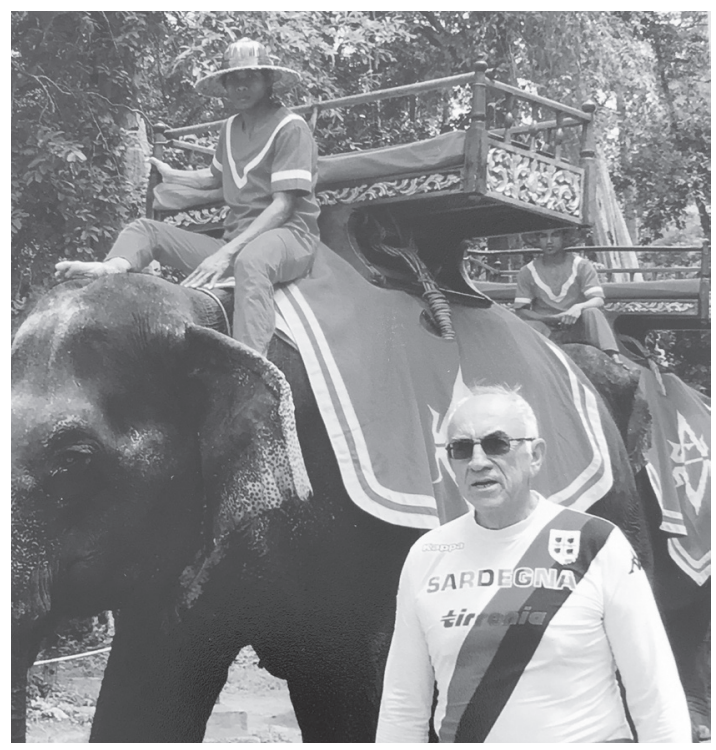

desiguales, violentos y de corrupción entonces ese es el meollo, ya el apego a los equipos tecnológicos es secundario.

3. La motivación es algo esencial en el aprendizaje. ¿Pero no cree usted que la enseñanza se ha concentrado más en la memorización que en la comprensión? Y es que solo un maestro que sabe motivar logra llevar por el camino de la comprensión, ¿no?

En la cultura de ahora, de los millennials todo es visual. Yo me he leído el libro de Piketty, todo El Capital, Millenium, en fin, porque estoy apasionado. Pero ellos tienen todo en un video; afuera tienen un paisaje y usted le pone el tablero, letras negras con un fondo blanco, cómo quiere comparar una cosa seca, un cadáver de conocimiento, es una momia el conocimiento. Entonces él o ella dicen me voy para la marcha o para la plaza. Hay una pedagogía muy plana, muy pasiva.
Por ejemplo, hace poco una profesora de otra universidad dijo: "ninguno de los 35 puede hacer una reseña sin ningún error" en su carta de renuncia, y un estudiante le dice que también es culpa de ella. Es importante la retroalimentación de un trabajo; yo corregí línea por línea un trabajo de 192 páginas, y por votación del grupo se aceptó que se publicara con las correcciones, eso no lo hacen todos los profesores. Además en el trabajo en grupo, si uno puede pasar por todos, nadie se va a meter con un vago, y en el mundo real se tiene que trabajar en grupo.

4. ¿Cuál es el caso más raro (difícil o asombroso, o ambos) que ha tenido como profesor?

Encontrar un muchacho que me arremedaba. Yo quería ponerle cero y sacarlo, pero me arremedaba muy bien, hacía preguntas terribles y yo quería expulsarlo de clase, pero me obligaba a leer. Entonces un día le dije: ¿por qué no sale a burlarse de los que hacen las bombas, de los que hacen las guerras, perjudican a los pobres y contaminan? Él llegó a la televisión y lo mataron, fue Jaime Garzón.

5. ¿Se arrepiente de algo como profesor?

Haber tenido a Jaime Garzón en el escritorio, contarle algunas ideas de economía política y las cosas que él decía sobre los militares, sobre la injusticia; al pensarlo, yo me siento responsable. La genialidad de él no está en discusión, yo hubiera querido ser un Jaime Garzón pero no soy capaz. Canto a veces en público, hago poesía en público y actúo con mis estudiantes. La educación es el único medio de movilización social en una sociedad tan injusta como la nuestra. 